\title{
Study on the Contribution Rate Variation of Teaching and Research of University Teachers Based on the Joint Benefit Assessment Method*
}

\author{
Chunlei Qin ${ }^{1}$ \\ Central University of \\ Finance and Economics
}

\author{
Wei Zhang ${ }^{2}$ \\ Central University of \\ Finance and Economics
}

\author{
Yanchun $\mathrm{Zhu}^{3}$ \\ Beijing Normal University
}

\begin{abstract}
With the deepening of higher education reform in China, the disjunction between teaching and research is becoming more and more serious. How to actively construct the coordination mechanism of teaching and research has become a constant concern of education researchers and practitioners. The existing research have constructed the evaluation models of teaching and research respectively from various perspective, but lack comprehensive consideration for the joint benefit of teaching research. Therefore, this paper constructed the joint assessment model by adopting the data envelopment analysis method. The contribution rate variation of teaching and scientific research was analyzed, the joint benefits of teaching and research was calculated and the teaching slackness and research slackness were inspected. The empirical results show that associate professors and teachers with 3 to 10 years of teaching experience rank the first two by the joint benefit of teaching and research. They are the main undertaker of university teaching and scientific research activities. In addition, the professional title promotion will not cause teaching slackness, but is quite easy to induce research slackness. These empirical results could provide some practical guidance and empirical evidence for continuous study of the relationship between teaching and scientific research and the policy formulation.
\end{abstract}

\section{Keywords}

Relationship between Teaching and Research $\bullet$ Contribution Rate $\bullet$ Joint Benefit Assessment - Data Envelopment Analysis

\footnotetext{
*The work was supported by Project of Party construction, ideological and political work in Central University of Finance and Economics (Grant No.DJB18001), Education and teaching method project in Central University of Finance and Economics (Grant No.040950317001), the foundation for Key Research Items in Teaching Reform Program of Central University of Finance and Economics (Grant No. JG201610).

${ }^{1}$ Office of Human Resources, Central University of Finance and Economics, Beijing 100081, China. Email: qc10801@126.com ${ }^{2}$ School of Information, Central University of Finance and Economics, Beijing 100081, China. Email: weizhang@cufe.edu.cn ${ }^{3}$ Correspondence to: Yanchun Zhu, Business School, Beijing Normal University, Beijing 100875, China. Email: kddzw@163.com
} 
The teaching and research of colleges and universities is the basic way to promote the growth of talents and create leading elites, and the main embodiment of the core competitiveness of universities. There is a complex relationship between teaching and research work. The two are both mutually benefiting from each other and are mutually contradictory (Clark, 1997; Witte et al., 2013; Baker, 1986). The relationship between teaching and research is an important issue that has been constantly concerned by education researchers and practitioners. To correctly handle the relationship between the two is of great significance to speed up the construction of the talent team, improve the quality of higher education, and promote the development of teachers' personal career (Verburgh, 2007).

With the deepening of the higher education reform in China, the social value of university education has changed and the social functions undertaken by the university is undergoing changes under the influence of many external factors (Fang, 2012). The relationship of teaching and research in domestic universities is at the crossroads--continue to split, mutually balanced or remain positive interaction. It is a major institutional choice facing the universities ( $\mathrm{Wu}, 2012)$. With the implementation of the higher education accountability system and the aggravation of international competition among universities as well as the interest in and pursuit for the university prestige, relevant Chinese government departments put forward the strategy of "establishing research-orientated universities", which intensifies the emphasis on and reward to the research and related activities of university professors. The implementation of this strategy has led to the differentiation of teaching and research in colleges and universities, which has intensified the separation of teaching and research. This separation not only occurs at the institutional level, but also to the teacher developmental system. Many universities classify and manage teachers through setting teaching positions, research positions, and teaching and research positions. However, in professional title promotion, the scientific research performance is still deemed as the main assessment index. This kind of situation that "emphasizes research and looks down on teaching" is becoming more and more obvious as time goes on (Fulton and Trow, 1974). "Scientific research drifting" and "teaching drifting" are becoming increasingly prominent.

In the market economy environment featuring rapid technology development and increasingly high benefit, the application-oriented, industrialized, and economic research activities are apparently incompatible with the function of talent cultivation of universities in terms of target, content and process, which is not good to the harmonious development of the teaching and research of universities. On the basis of combing the relationship between teaching and research, from the perspective of optimizing the performance appraisal system, the academic circles constructed corresponding evaluation systems targeting classroom teaching quality, research input and output efficiency, the supporting role scientific research to teaching, etc. Witte and Rogge (2010), Cai and Xu (2014), Liu (2014), Zhou and Ma (2013), Zhao (2014) and Zhang (2014) using such theoretical methods as questionnaire survey (Liu et al., 2010; Chen and $\mathrm{Wu}, 2014)$, level analysis method, and data envelopment analysis. This provides abundant empirical evidence for the improvement of teaching quality, the enhancement of the system for teacher development and the intensification of research and teaching integration. However, these researches still adhere to the thought of teaching and research separation and respective evaluation systems are established for the 
teaching activity and research work, lacking a comprehensive consideration of the interaction of the two (Cadez et al., 2015; Lu and Liu, 2006); moreover, in the unbalanced pattern of "emphasizes research and looks down on teaching, how about the joint benefits of teaching and research of university teachers? Will they have a slack attitude towards their job after getting promoted? What measures can be taken to effectively address these imbalances. Further probes into these questions will be expected. Therefore, based on the teaching and research data collected from a research university, and adopting the data envelopment analysis method, this paper measures the teaching and research performance of teachers, probes into the joint benefit of teacher' research and teaching, and analyzes the professional burnout, which provides empirical basis for improving the teachers' development system, teachers' evaluation system, and the intensification of the relationship between teaching and research. It also provides some theoretical guidance and practical reference for achieving the coordinated development of teaching and research.

\section{Overseas and Domestic Research status}

In view of such prominent problems as unbalanced positioning, mutual disjunction and inaccurate evaluation of teaching and research in China's current higher education practice, domestic and foreign scholars expounded on the causes of these problems by using the social survey (Liu et al., 2010; Chen and Wu, 2014), game theory (Zhang et al., 2011), economics and other theories from the aspects of historical evolution (Wu, 2012), phenomenal description (Yang et al., 2011), internal relation (Xu et al., 2011; Wu, 2012), etc. and from the perspectives of field domain (Wu, 2011) and non-linear relationship (Liu and Wu, 2010; Wu and Zhang, 2012). They thought the main reasons include the irrationality of government's quality control and resource allocation system, imperfection of the academic evaluation and teacher promotion system in universities, unsoundness of the academic accreditation mechanism inside the academic community and the deviation of the values and ideas of universities and teachers (Xu et al., 2011; Cao, 2011; Ramsden and moses, 1992; Yan, 2012) and suggested that the establishment of reasonable evaluation standard, establishment of scientific evaluation systems, and optimizing the teaching and research incentive mechanism are the favorable measures to alleviate the imbalance from such aspects as system construction, research evaluation, discipline construction and talent cultivation (Xu et al., 2011; Wu and Zhang, 2012; Li, 2017; Li and Xu, 2011).

In order to solve the imbalance of teaching and scientific research, according to the modern education management theory, scholars both at home and abroad determined the important factors that influence the teaching and research quality starting with an open-ended questionnaire and constructed corresponding teaching-oriented and research-oriented evaluation systems (Zhou and Ma, 2013; Zhao, 2014) by adopting such approaches as level analysis (Witte and Rogge, 2010), data envelopment analysis Cai and Xu (2014), structural equation model (Liu, 2014; Cadez et al., 2015), etc. For example, Cai and Xu (2014) constructed the indicator system to evaluate the teaching quality of the undergraduate courses, which matches the orientation of the university, and then probed into the essential structure existing among multiple indicators using a multivariate statistical method to obtain a structured quality evaluation index system model for 
classroom teaching. At last, they finished the affirmation of the index weight using the analytic hierarchy process of group decision (Liu, 2014). Taking partial teachers at some university in China as samples, Zhao (2014) made quantitative analysis of the relative profit of their teaching quality evaluation using DEA model and put forward the approach to improve the teaching quality. Based on the actual data of teachers' teaching quality evaluation, Zhang (2014) firstly classified the indicators into three latent variables, i.e. sense of responsibility, teaching method and teaching level by adopting the factor analysis method; and then established the teaching quality evaluation model using SEM technology to carry out inspection and quantitative analysis.

For scientific research evaluation, scholars mostly use empirical methods to analyze the relationship between scientific research and teaching and measure the research efficiency. For example, Cadez, Dimovski and Groff (2015) based on the teaching and research data of Maribo University in Slovenia, constructed a multiple regression model and carried out empirical studies on the relationship between teaching and scientific research. The results showed that the number of scientific research achievements has nothing to do with the teaching quality, but the quality of the research results is positively correlated with the quality of teaching. Based on the analysis of the efficiency and variation trend from 2000 to 2002 of scientific researches in 54 moe-administrated universities at different regions, Lu and Liu (2006) found that the scientific research efficiency of $46.3 \%$ of universities needs to be further improved and that the research efficiency of universities in eastern, central and western regions presented a declining trend. In addition, the research efficiency and scale efficiency of universities in different regions fluctuate, but the change trend is different. They proposed to establish the efficiency-based scientific research resource allocation mechanism for universities, and guide colleges and universities to pay attention to the inputoutput efficiency of scientific research activities, thus optimizing regional research resources allocation.

To sum up, although domestic and foreign scholars carried out independent evaluation to the teaching performance and research performance in colleges and universities, or made integrated assessment on the teaching and research benefits of partial colleges and universities, and put forward corresponding benefit improvement suggestions accordingly, nobody has made integrated assessment on the teaching and research benefits of a particular teacher. Therefore, based on the abovementioned situation and taking partial teachers at some university in Beijing as samples, this paper calculates the joint benefits of teaching and research of each sample to put forward suggestions on improving the joint benefits. This will provide scientific foundation and basis for policy making and for the further study of the relationship between teaching and research.

\section{Model Building}

Data Envelopment Analysis (DEA) is a mathematical programming method to evaluate the relative efficiency of homogeneous decision units with multiple inputs and outputs, which is a non-parametric evaluation method (Charnes et al., 1978). Compared with traditional evaluation methods such as 
hierarchical analysis and fuzzy comprehensive evaluation, the most significant advantages of this method include (Wei, 2001): (1) Effective decision unit is used to define the forefront of production possibility set, and the efficiency of the corresponding decision unit is measured using the weighted sum of the output variables and input variables, therefore, there is no need to consider the production function relation between input and output; (2) There is also no need to anticipate any parameters or weight, and the weight of input and output variables are obtained through solving corresponding DEA model, so the results are fairly objective, which can avoid the impact of subjective factors on efficiency evaluation to a large degree. Therefore, the data envelopment analysis method is introduced into the evaluation of the joint efficiency of teaching and research, trying to objectively use all kinds of evaluation indexes to evaluate the result of efficiency.

\section{Original DEA Model}

The DEA model is first used to analyze the relative efficiency of different decision units with multiple inputs and multiple outputs, and its original expression is as follows, assuming that the yield of scale is constant.

$$
\max z=\frac{\sum_{r=1}^{s} \mu_{r} y_{r j}}{\sum_{r=1}^{m} v_{i} x_{i j}}, \text { s.t. }\left\{\begin{array}{c}
\frac{\sum_{r=1}^{s} \mu_{r} y_{r j}}{\sum_{r=1}^{m} v_{i} x_{i j}} \leq 1 \\
\mu_{r} \geq 0, r=1, \ldots, s \\
v_{i} \geq 0, i=1, . ., m
\end{array}\right.
$$

Where, efficiency is defined as the ratio of output divided by input, and the limiting condition that efficiency is smaller than or equals to 1 is added. After determining the front surface, the distance from the different decision units to the leading surface is calculated in order to determine the relative efficiency.

\section{Linear programming model after Charnes-Cooper transformation}

Corresponding linear programming model can be obtained after the original fractional expression goes through the Charnes-Cooper transformation. Its expression is as follows:

$$
\max z=\sum_{r=1}^{s} \mu_{r} y_{r o}, \text { s.t. }\left\{\begin{array}{l}
\sum_{r=1}^{s} \mu_{r} y_{r j}-\sum_{r=1}^{m} v_{i} x_{i j} \leq 0 \quad(j=1,2, \ldots, n) \\
\sum_{r=1}^{m} v_{i} x_{i o}=1 \\
\mu_{r} \geq 0, v_{i} \geq 0
\end{array}\right.
$$


Where, $m$ is the number of input indicators and $s$ is the number of output indicators; $n$ is the number of decision units; $x_{i j}$ is the application amount of $D M U_{j}$ at the ith input and $y_{i j}$ is the yield of $D M U_{j}$ at the rth output; the decision variables of $\mu_{r}$ and $v_{i}$ are the combination coefficients of output and input respectively.

\section{Construction of Joint DEA Model}

Since only a single kind of benefit can be evaluated using formula (2), this paper improves the model to some degree, and constructs the combined DEA model, expecting to make evaluations on the joint benefit of research and teaching of different decision units. Considering that different teachers in colleges need to take on the task of teaching and research at the same time, and that the investment in teaching and research cannot be divided according to certain criteria, the method of partial input resources sharing is adopted in this paper. The sharing coefficient $p$ of duration since entering the school and the sharing coefficient $q$ of professional title are set. The overall amount of each shared resource is set as 1 . When the ratio of scientific consumption and duration since entering the school is $p$, the amount of the resource consumed in education is 1-p; when the ratio of scientific consumption and professional title is $q$, the amount of the resource consumed in education is $1-q$. The model constructed is as follows:

$$
\max z=R_{o}+T_{o}, \text { s.t. }\left\{\begin{array}{l}
R_{o}=\sum_{r=1}^{2} \mu_{r} y_{r o} \\
T_{o}=\sum_{r=3}^{4} \mu_{r} y_{r o} \\
\sum_{r=1}^{2} \mu_{r} y_{r o} \leq p v_{1} x_{1 j}+q v_{2} x_{2 j}+v_{3} x_{3 j} \quad(j=1,2, \ldots, n) \\
\sum_{r=3}^{4} \mu_{r} y_{r j} \leq(1-p) v_{1} x_{1 j}+(1-q) v_{2} x_{2 j}+v_{4} x_{4 j}+v_{5} x_{5 j}+v_{6} x_{6 j} \quad(j=1,2, \ldots, n) \\
p v_{1} x_{1 o}+q v_{2} x_{2 o}+v_{3} x_{3 o}=1 \\
(1-p) v_{1} x_{1 o}+(1-q) v_{2} x_{2 o}+v_{4} x_{4 o}+v_{5} x_{5 o}+v_{6} x_{6 o}=1
\end{array}\right.
$$

Where, $R_{0}$ stands for the benefit of scientific research and $T_{0}$ refers to the teaching performance. According to Formula (3), the sum of research benefit and teaching benefit is the maximum. Formula (3) is the transformations of Formula (2) and limits the scope of the sharing coefficient, which is set arbitrarily. Based on Formula (3), the value of the combination coefficient is a nonnegative number.

\section{Research Data Collection and Processing}

\section{Data Collection}

In this paper, partial teachers in a university in Beijing are taken as the empirical objects. In order to study the research and teaching workload of different groups between 2012 and 2016, this paper collects their annual teaching quantity, lectures amount, scientific research workload, years of teaching, professional title and time when the professional title was obtained. In order to study the joint benefit of teaching and research of different individuals in the faculty in 2016, this paper collects relevant data of research and teaching input and output: the professional title, years of teaching and scientific research 
workload are taken as the research input; the number of published papers and the number of participated projects are taken as the research output; the professional title, years of teaching, sum of teaching and lectures and sum of non-teaching and non-lecture activities are taken as the teaching input; the teaching evaluation scores and students' overall impression scores are taken as the teaching output.

\section{Data Processing}

Qualitative analysis of data processing. The qualitative analysis data of teaching and research load and contribution rate of different groups are composed of two parts: the teaching load, which includes academic year, teacher's name, teaching quantity, amount of lectures, professional title, and years of teaching; the research load, including academic year, teacher's name, research quantity, professional title, and years of teaching.

Quantitative analysis of data processing. The composition of the quantitative analysis data of the joint benefit of individual research and teaching is shown in table 1.

Table1

Input-output table of Scientific Research and Teaching

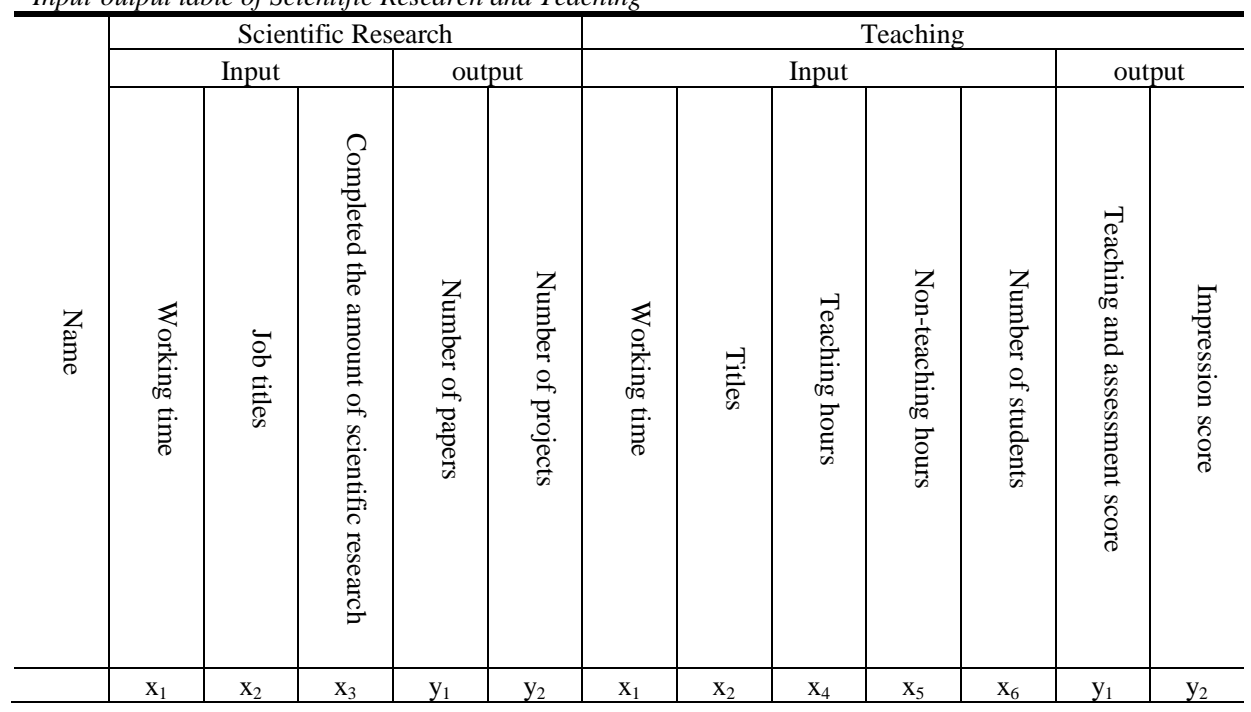

The data in the table are processed because numerical values other than positive numbers are not allowed to appear in DEA model.

(1) Character manipulation: the title is a character, which requires value assignment. Here, the value of 1 is assigned to teaching fellow, 1.2 is assigned to associated professor and 1.5 is assigned to professor; (2) non-zero treatment: the scientific research quantity of partial teachers is 0 , since the value of actual scientific research quantity is rather large (over 100), 0 is changed to 0.1 , which will not affect the final 
results. (3) standard processing: in this paper, Formula (4) is adopted to carry out standardized processing of all the scientific research output data.

$$
Y=0.1+0.9 \frac{X-X_{\min }}{X \min _{\max }}
$$

Where, $X$ is the original value of scientific research output, $Y$ is the scientific output value after adjustment, $X_{\min }$ is the minimum value and $X_{\max }$ is the maximum value of this variable.

\section{Empirical Analysis}

Qualitative analysis method was adopted to study the load and change rate of teaching and research, i.e. from the perspectives of teaching and scientific research and using such data as years of teaching, professional title, teaching quantity and research quantity, this paper probes into the teaching and research workload in different years of teachers with different years of teaching experience and professional titles and the proportion of the teaching and research workload assumed by this group of teachers in the teaching and research workload assumed by all the teachers, and then from the perspective of age and professional title, this paper explores whether teachers will have a slack attitude towards their work after the professional title appraisal. In order to examine the joint benefit of teaching and research of individual teachers, quantitative analysis was carried out in this paper based on the input and output of teaching and research, from the perspective of different teachers.

\section{Qualitative Analysis}

Teaching contribution rate. The ratio line chart is plotted after the teachers are grouped according to professional titles and the teaching and lecture workload, the contribution rate of teaching and lecture and the proportion of each group of teachers in the total number are calculated. The chart is shown in Figure 1, Figure 2 and Figure 3. Where, the teaching workload includes lecture amount and non-lecture teaching workload.

As can be seen from Figure 3, the proportion of associate professors in the total number had been the highest in the five years, and this proportion was slowly rising as a whole. The proportion of professors in the total number of teachers showed a gentle trend between 2012 and 2014, but presented a rising trend from 2014 to 2016 . The proportion of the lecturers in the total number of teachers had been decreasing in the five years, with a large amplitude. It is found that the benefit of the group of professors and associate professors in other years also remained relatively stable after making a comparison between the broken line slopes representing the associate professor group in corresponding year in Figure 1 and Figure 2, Figure 2 and Figure 3. Although the teaching contribution rate and lecture contribution rate of teachers with different professional titles will be affected to some extent by the number of people in this group, and the lecture contribution rate of different groups are affected by such factors as whether to instruct students' internship, whether to guide practical innovation projects and whether to guide the graduation project of 
undergraduates and graduate students, generally speaking, the teaching and lectures by the associate professor group have been keeping at a fairly high level, and the associate professor group is also the major group engaged in teaching and giving lecture.

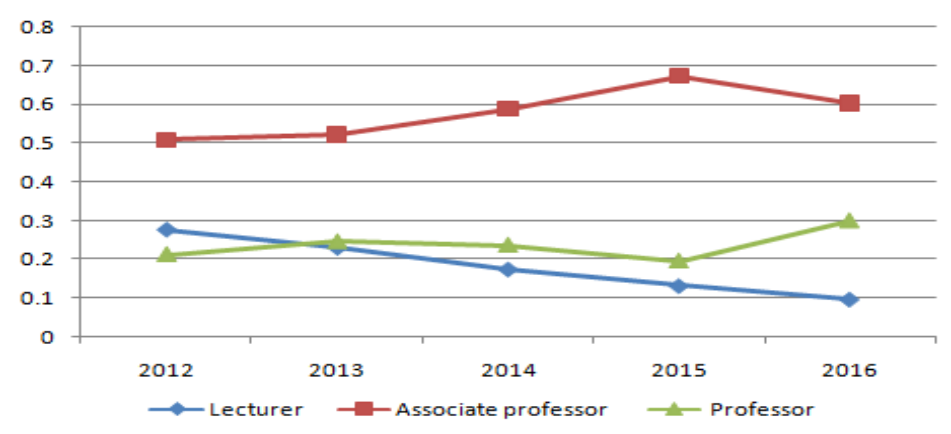

Figure 1. Change of the teaching contribution rate of teachers grouped by professional titles.

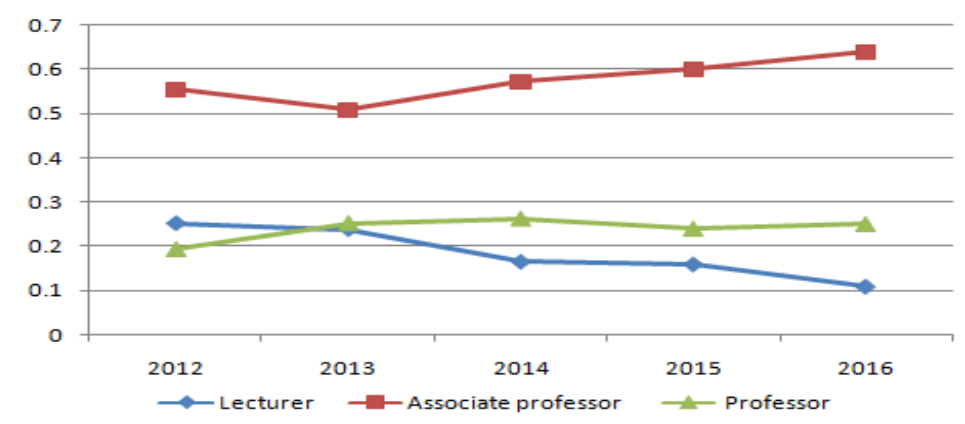

Figure 2. Change of the lecture contribution rate of teachers grouped by professional titles.

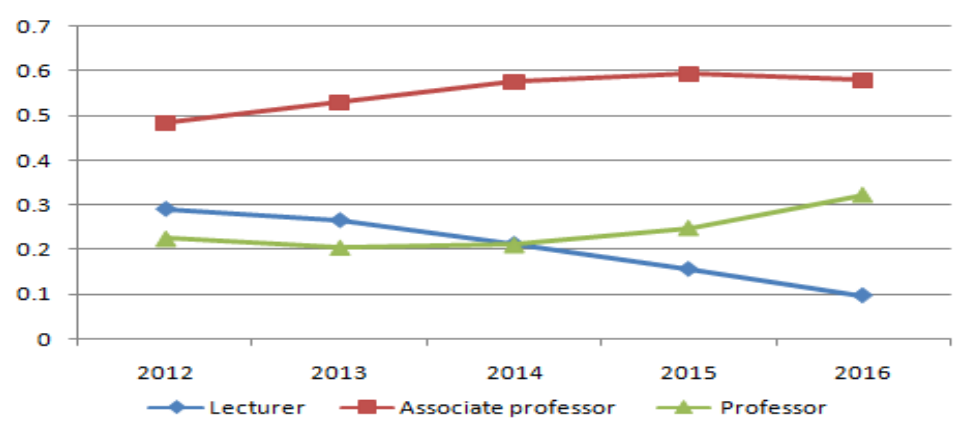

Figure 3. Proportion of teachers with the same professional title in the total number of teachers.

The ratio line chart is plotted after the teachers are grouped according to years of teaching and the teaching and lecture workload, the contribution rate of teaching and lecture and the proportion of each group of teachers in the total number are calculated. The chart is shown in Figure 4, Figure 5 and Figure 6. Where, the teaching workload includes lecture amount and non-lecture teaching workload. Here, when 
$x$ is smaller than or equals to 3 , the group is called the group of young teachers; when $x$ is larger than 3, but smaller than or equals to 10 , the group is called the group of middle-aged teachers; when $x$ is larger than 10 , the group is called the group of senior teachers.

As can be seen from Figure 6, the proportion of the group of middle-aged teachers in the total number had been the highest in the five years, and this proportion was fluctuating as a whole. The proportion of senior teachers in the total number of teachers showed a rising trend between 2012 and 2014, but presented a gentle trend from 2014 to 2015. This proportion continued to rise thereafter. The proportion of the group of young teachers in the total number of teachers had been decreasing in the five years, with a large amplitude.

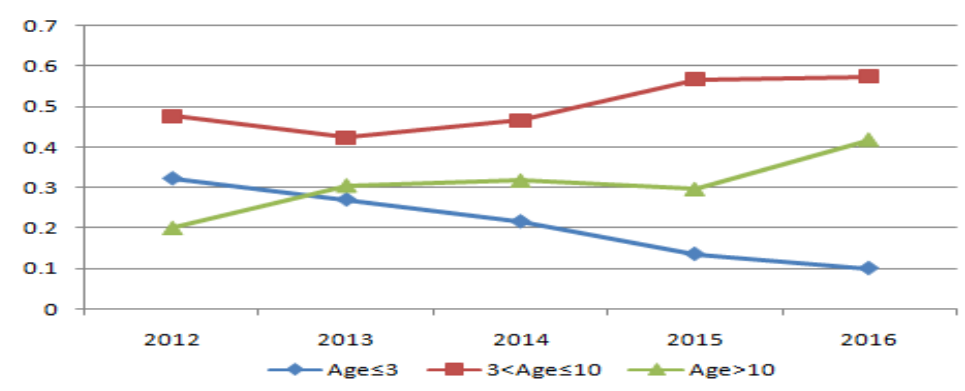

Figure 4. Change of the teaching contribution rate of teachers grouped by years of teaching.

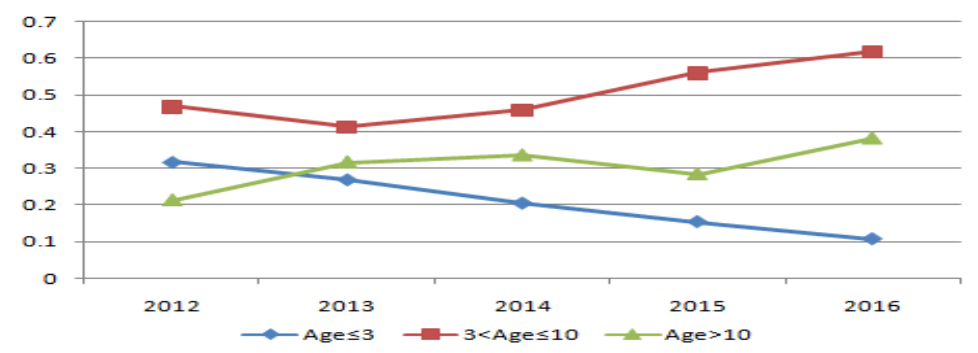

Figure 5. Change of the lecture contribution rate of teachers grouped by years of teaching.

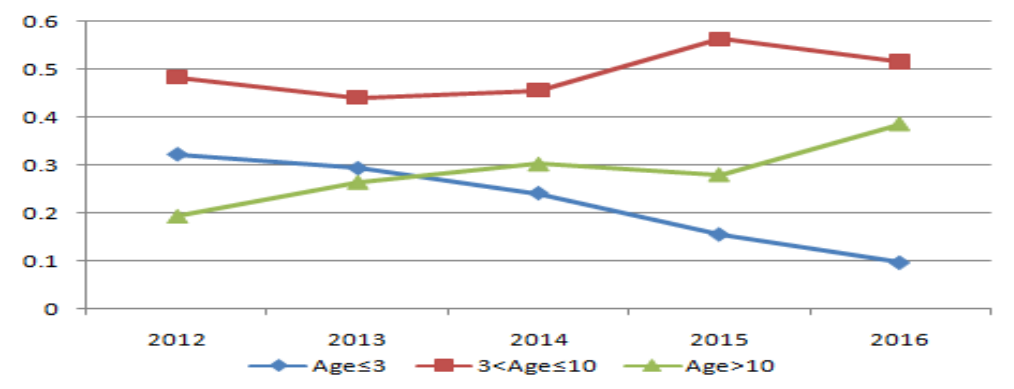

Figure 6. Proportion of teachers with the same years of teaching experience in the total number of teachers. 
After making a comparative analysis of Figure 4 and Figure 5, it can be seen that the broken line representing middle-aged teachers has been at the highest point and maintained an upward trend in general; the broken line representing young teachers shows a downward trend, while the broken line representing senior teachers takes on an upward trend, and the two have a point of intersection in 2013.

After making a comparison between Figure 4 and Figure 5and combining the line trend in Figure 6, we found that although the teaching and lecture contribution rate of teachers with different years of teaching experience will be affected to some extent by the number of teachers in this group, and the lecture contribution rate of different groups are affected by different factors, in general, the teaching and lecture benefits of middle-aged teachers had been remaining at a fairly high level. The middle-aged teachers are the main undertaker of teaching and lecturing.

Research contribution rate. The ratio line chart is plotted after the teachers are grouped according to professional titles and the research workload, the contribution rate of research and the proportion of each group of teachers in the total number are calculated. The chart is shown in Figure 7 and Figure 8.

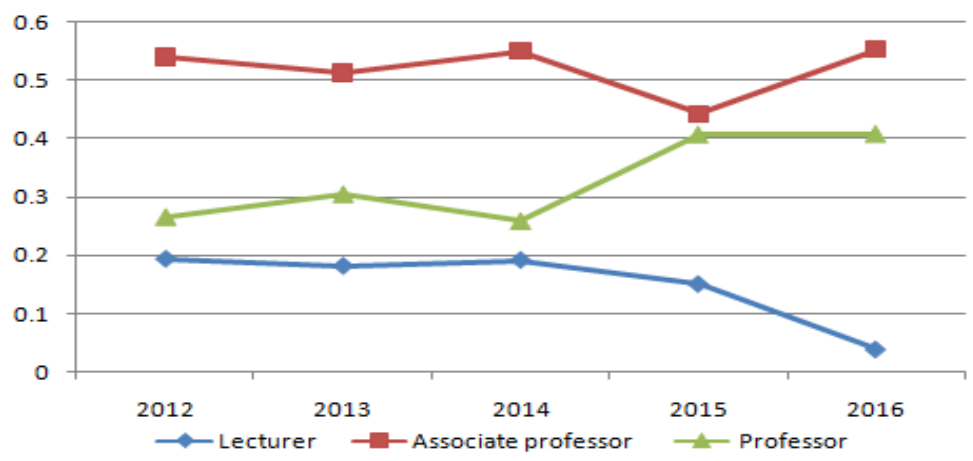

Figure 7. Change of the research contribution rate of teachers grouped by professional titles.

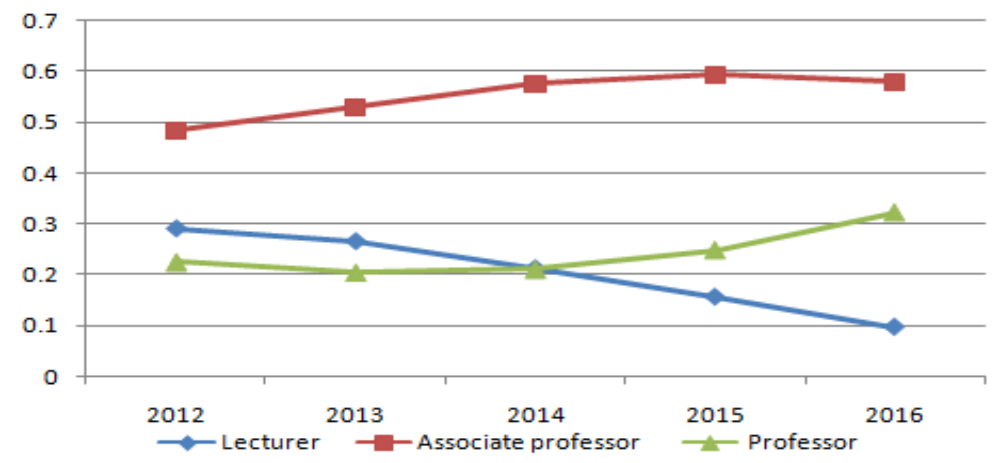

Figure 8. Proportion of teachers with the same professional title in the total number of teachers. 
As can be seen from Figure 7, the research contribution rate of the group of lecturers had been at the lowest position and sharply declined after 2014. The research contribution rate of the group of associate professors had been at the highest position, but fluctuated sharply and bottomed out at the end of 2015. In addition, the research contribution rate of professors had been at a moderate level and became stable after reaching its peak in 2015. In combination with the teaching contribution rate, the reasons for the decline of research contribution rate is that the overall teaching contribution rate of associate professors in 2015 surged and reached its peak of the five-year period, so the amount of scientific research drastically reduced under the preconditions of limited personal energy and that since the overall teaching contribution rate of the professor group reached the minimum value of the five years in 2015 and they put more efforts into scientific research, the amount of scientific researches rose sharply accordingly.

As can be seen from Figure 8, the proportion of associate professors in the total number of teachers is the highest in the five years, and the proportion is slowly rising. The proportion of professors in the total number of teachers is on the rise, but it reached its lowest point in 2013. The proportion of lecturers in the total number of teachers is decreasing, which became smaller than that of professors since 2014 and the gap was getting larger and larger year by year.

After comparing the contribution rate curve of associate professor and the curve of proportion of associate professors in the total number of teachers in Figure 7 and Figure 8 respectively, we found that although the proportion of associate professors in the total number of teachers keeps rising, the contribution rate curve fluctuates a lot. But the curve OF research contribution rate has always been at the highest position, so the associate professor group is the main research group.

The ratio line chart is plotted after the teachers are grouped according to years of teaching and the scientific research workload, the contribution rate of research and the proportion of each group of teachers in the total number are calculated. The chart is shown in Figure 9, and Figure 10.

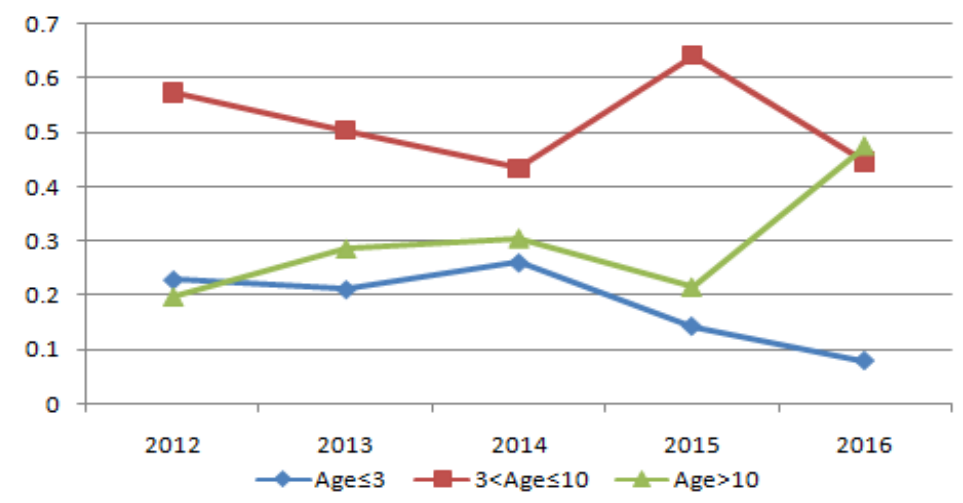

Figure 9. Change of the research contribution rate of teachers grouped by years of teaching. 


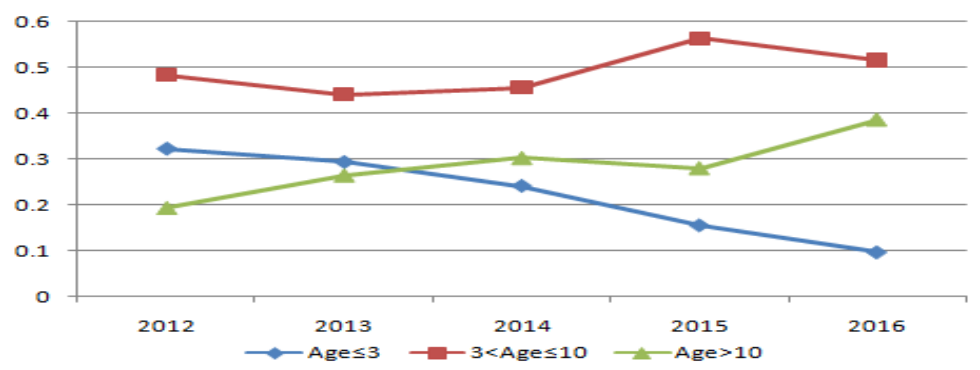

Figure 10. Proportion of teachers with the same years of teaching in the total number of teachers.

Figure 9 and Figure 10 show that the proportion of middle-aged teachers with 3-10 years of teaching experience had been the highest in the five years and the proportion fluctuates as a whole. The proportion of senior teachers with more than 10 years of teaching experience presented an overall rising trend and remained stable in 2014 and 2015. The proportion of young teachers with less than 3 years of teaching experience had been trending down in the five years, with a large amplitude. Although the proportion of middle-aged teachers had been fluctuating around 50\%, the proportion of the population had been lower than the contribution rate of the group, which means that fewer people have made more contributions.

To sum up, although the scientific contribution rate of teachers with different years of teaching is to some extent under the influence of the number of teachers in this group, and the scientific research contribution rate of different groups are influenced by different factors, in general, the benefit of scientific research of middle-aged teachers group has maintained at a higher level, therefore, it can be concluded that the middle-aged teachers are the most important research group among the college teachers.

Slackness analysis: In this part, the author collected the list of teachers who have achieved professional title promotion for either teaching or research performance during the period from 2012 to 2016 and found the data of their research and teaching quantity of the year when they were promoted and of the year after they were promoted. According to the standard, we can tell whether they had a slack attitude towards their research and teaching.

According to statistics, from 2012 to 2015, total eight teachers have achieved professional title promotion. Analysis was made to each teacher's slackness in teaching and scientific research and the results are shown in Figure 11, 12 and 13.

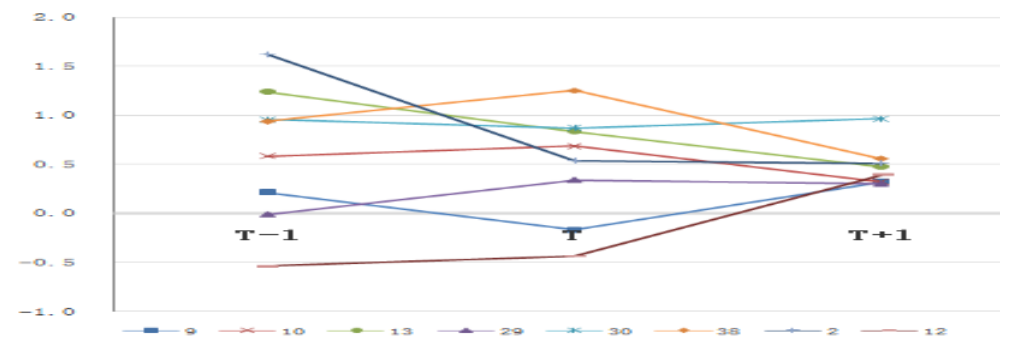

Figure 11. Slackness in teaching. 


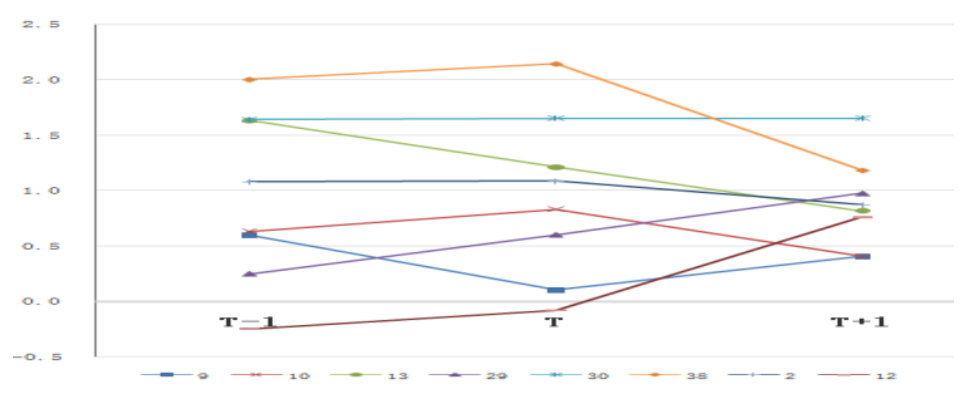

Figure 12. Slackness in lecturing.

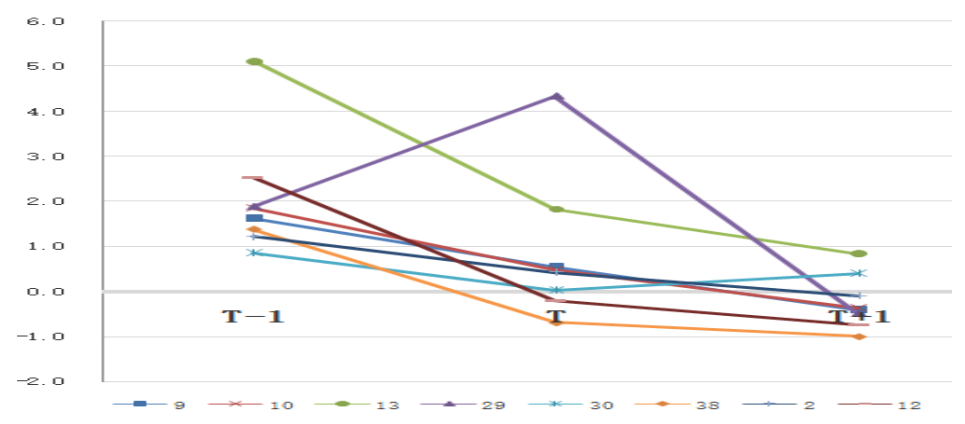

Figure 13. Slackness in scientific research.

It can be seen from Figure 11, 12 and 13 that $20 \%$ of teachers were slack in teaching after they achieved professional title promotion, and $60 \%$ of teachers were slack in the research. Therefore, it can be concluded that the promotion of professional title is not easy to cause teaching slacking, but it is easy to induce scientific research slackness.

Possible reasons of the abovementioned results are as follows: Teaching is a compulsory target that must be achieved, so most teachers will maintain a sound teaching status and it does not affect the professional title promotion of teachers, while scientific research is not a compulsory target and teachers can decide whether to conduct research based on their own plan, so at the year of professional title promotion, teachers will spent more time on scientific research to achieve professional title promotion. However, after this target is achieved, quite a number of teachers will slack off and reduce their research workload. In this case, research incentive policies shall be made targeting all groups. If they can meet the quota of scientific research workload after deduction after they achieved professional title promotion, they will be awarded. The aim of this measure is to motivate teachers to actively complete scientific research after teaching. 


\section{Quantitative Analysis}

Based on the collection and arrangement of the teaching and research input and output data of all the teacher samples in 2016, the original table of joint benefit of scientific research and teaching is formed. On this basis, the joint benefit of scientific research and teaching under the premise condition of unchanging scale return can be obtained through using Matlab to solve the quadratic programming problem of the combined DEA model. The specific results are shown in Table 2.

Table 2

Evaluation Score Sheet of the Joint Benefit of Scientific Research and Teaching

\begin{tabular}{|c|c|c|c|c|c|c|}
\hline Ranking & Number & $\begin{array}{c}\text { Scientific } \\
\text { research benefit }\end{array}$ & $\begin{array}{c}\text { Teaching } \\
\text { benefit }\end{array}$ & $\begin{array}{c}\text { Comprehensive } \\
\text { benefit }\end{array}$ & Job titles & $\begin{array}{l}\text { years of } \\
\text { teaching }\end{array}$ \\
\hline 1 & 15 & 1.00 & 1.00 & 2.00 & Associate professor & 5 \\
\hline 2 & 5 & 1.00 & 1.00 & 2.00 & Lecturer & 1 \\
\hline 3 & 1 & 1.00 & 1.00 & 2.00 & Lecturer & 1 \\
\hline 4 & 7 & 1.00 & 1.00 & 2.00 & Lecturer & 1 \\
\hline 5 & 22 & 1.00 & 1.00 & 2.00 & Associate professor & 19 \\
\hline 6 & 13 & 1.00 & 1.00 & 2.00 & Associate professor & 7 \\
\hline 7 & 28 & 1.00 & 0.97 & 1.97 & Lecturer & 1 \\
\hline 8 & 33 & 1.00 & 0.86 & 1.86 & Associate professor & 4 \\
\hline 9 & 38 & 0.96 & 0.83 & 1.79 & Associate professor & 10 \\
\hline 10 & 25 & 1.00 & 0.79 & 1.79 & Professor & 17 \\
\hline 11 & 36 & 0.96 & 0.82 & 1.78 & Associate professor & 15 \\
\hline 12 & 21 & 1.00 & 0.76 & 1.76 & Professor & 14 \\
\hline 13 & 23 & 0.77 & 0.99 & 1.76 & Lecturer & 9 \\
\hline 14 & 35 & 0.94 & 0.82 & 1.76 & Associate professor & 11 \\
\hline 15 & 30 & 0.89 & 0.83 & 1.72 & Associate professor & 3 \\
\hline 16 & 37 & 0.71 & 0.98 & 1.70 & Lecturer & 6 \\
\hline 17 & 32 & 0.64 & 0.97 & 1.61 & Lecturer & 2 \\
\hline 18 & 19 & 0.59 & 0.99 & 1.59 & Lecturer & 1 \\
\hline 19 & 16 & 0.53 & 0.96 & 1.50 & Lecturer & 6 \\
\hline 20 & 39 & 0.53 & 0.95 & 1.48 & Lecturer & 5 \\
\hline 21 & 14 & 0.60 & 0.81 & 1.42 & Associate professor & 8 \\
\hline 22 & 8 & 0.40 & 1.00 & 1.40 & Professor & 10 \\
\hline 23 & 6 & 0.38 & 1.00 & 1.38 & Lecturer & 2 \\
\hline 24 & 11 & 0.53 & 0.81 & 1.34 & Associate professor & 15 \\
\hline 25 & 4 & 0.49 & 0.82 & 1.31 & Associate professor & 9 \\
\hline 26 & 3 & 0.47 & 0.83 & 1.30 & Associate professor & 7 \\
\hline 27 & 10 & 0.46 & 0.80 & 1.25 & Associate professor & 8 \\
\hline 28 & 18 & 0.43 & 0.82 & 1.25 & Associate professor & 10 \\
\hline 29 & 26 & 0.24 & 1.00 & 1.24 & Associate professor & 10 \\
\hline 30 & 31 & 0.56 & 0.68 & 1.24 & Professor & 19 \\
\hline 31 & 27 & 0.19 & 1.00 & 1.19 & Lecturer & 3 \\
\hline 32 & 12 & 0.48 & 0.67 & 1.15 & Professor & 11 \\
\hline 33 & 29 & 0.31 & 0.82 & 1.13 & Associate professor & 4 \\
\hline 34 & 9 & 0.21 & 0.87 & 1.08 & Associate professor & 8 \\
\hline 35 & 24 & 0.23 & 0.80 & 1.04 & Associate professor & 5 \\
\hline 36 & 2 & 0.33 & 0.70 & 1.03 & Professor & 10 \\
\hline 37 & 17 & 0.10 & 0.91 & 1.01 & Professor & 7 \\
\hline 38 & 20 & 0.16 & 0.83 & 0.98 & Associate professor & 16 \\
\hline 39 & 34 & 0.18 & 0.70 & 0.88 & Professor & 22 \\
\hline
\end{tabular}

It can be seen from the calculation of the results of the combined DEA model that the overall teaching efficiency of teachers participated in the grading of joint benefits scientific research and teaching in 2016 was fairly high, most surpassing 0.8 . The possible reason is that the evaluation method for teaching output 
is single and the result is relatively high. However, the research efficiency is quite different. Some teacher's research rating is the maximum of 1.00 , while some teacher's research rating is the minimum of 0.10 . One of the reasons for the great gap in scoring is that different teachers have different requirements for scientific research in the same year, resulting in a large gap in research output.

The abovementioned joint benefit is expressed with a scatter diagram, and the result is shown in Figure 14.According to the scatter diagram, the teachers can be divided into four different categories: "teachers with high teaching workload and high scientific research workload" (e.g., 1, 4), "teachers with high teaching workload and low scientific research workload" (e.g., 23, 31), "teachers with low teaching workload and high scientific research workload" (e.g., 10, 12), and "teachers with low teaching workload and low scientific research workload" (e.g., 30, 39). Each group of teachers are ranked with the teaching benefit and scientific research benefit as the principal sorting conditions and teaching job title, research professional title, years of teaching as the secondary sorting conditions.

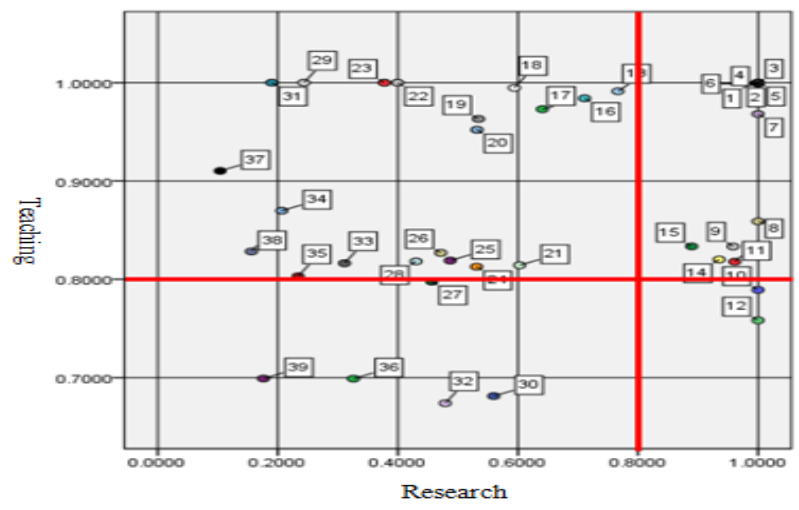

Figure 14. Scatter diagram of the joint benefit.

By analyzing the results, we can find out teachers with "high teaching benefit and high scientific research benefit" are mostly lecturers or associate professor with less than ten years of teaching experience. These teachers are strong in scientific research and teaching. The author believes that appropriate incentive policies shall be made to encourage these teachers to continue their development; teachers with "high teaching benefit and low scientific research benefit" are partially the lecturers who have just joined the school and without qualification for professional title promotion and are partially professors or associate professors with multiple years of teaching experience but unwilling to achieve a higher professional title. Both types of teachers are strong in teaching. However, the research capability of the former is uncertain, and the research capability of the latter is weak due to lacking of energy. As for the lecturers, continuous observation of their joint benefit development trend is needed, and for the latter, more evaluations shall be carried out to their teaching and appropriately mitigate the evaluations of their research; qualitative analysis cannot be carried out since the number of the sample of teachers with "low teaching benefit and high scientific research benefit" is small and the difference among samples is too large. But for this kind of situation, the author thinks that there can be more scientific research assessments and the pressure of 
teaching can be appropriately alleviated, in order to encourage them to put more energy into scientific research, thus improving the school's overall scientific research capability; teachers with "high teaching benefit and low scientific research benefit" are partially the lecturers who have just joined the school and without qualification for professional title promotion and are partially professors with multiple years of teaching experience. For the former, since they just joined this university and are not suitable to the environment, so their teaching benefit and research benefit are both low; as for the latter, since there is no room for achieving a higher professional title promotion, they have a slack attitude. As for the former, continuous observation of their joint benefit development trend is needed, and for the latter, more evaluations shall be carried out to their teaching in order, thus enhancing the overall teaching level of this university through taking full advantage of their multiple years of teaching experience.

\section{Conclusions}

Most of the existing teaching and research evaluation studies are carried out from a disconnected perspective. Respective evaluation models are constructed, lacking a comprehensive consideration of the interaction between teaching and scientific research. These studies are unable to better reflect the complementary relationship between teaching and scientific research, and are difficult to provide support for the formulation of policies and system for teachers' development. Therefore, based on the real data of teaching and scientific research in a university, a combined DEA model is established by using the data envelopment analysis. This paper analyzes the impact of different professional titles and teaching seniority on the contribution rate variation of teaching and scientific research in the past five years, calculates the joint benefit of teaching and scientific research, and investigates the teaching slackness and scientific research slackness after teaches achieved the promotion of professional titles. Empirical results show that: (1) The contribution rate of teaching and scientific research is the highest among the groups of associate professors and teachers with 3 and 10 years of teaching experience. They are the main force to undertake teaching and participate in scientific research activities. (2) Since the teaching workload is directly linked to the income of teachers, and the completion of scientific research workload is the basic condition for teachers to achieve professional title promotion, the promotion of professional title has no effect on teaching work, but it is easy to induce research slackness. (3) Compared with lecturers, professors, new teachers and old teachers, the joint benefit of teaching and scientific research of groups of associate professors and young teachers is higher. Based on the above conclusions, this paper puts forward a multilevel and humanized system for teacher development. As for the associate professors and teachers with less than 10 years of teaching experience, the implementation of flexible teaching and scientific research rewards can motivate them to complete teaching and research activities in a better way. For those teachers who have more than 10 years of teaching experience and fairly higher teaching benefit, schools can appropriately increase the percentage of scientific research workload abatement in teaching and research post audit, and they can better play their teaching advantages and improve the quality of teaching of the school through setting up teaching teams with new teachers. For the new teachers who have relatively high 
scientific research benefit, schools can appropriately reduce their teaching tasks, so that they can give full play to their advantages of scientific research.

Cantering around these empirical conclusions, bibliometrics, content analysis, case analysis and other methods are expected to be introduced into the coordination mechanism of teaching and research to promote the integration and cooperation of science and education and further improve the system of teachers' development in the future.

\section{References}

Baker, P. J. (1986). The helter-skelter relationship between teaching and research: A cluster of problems and small wins. Teaching Sociology, 14(1), 50-66. https://dx.doi.org/10.2307/1318299.

Cadez, S., Dimovski, V., \& Groff, M. Z. (2015). Research, teaching and performance evaluation in academia: The salience of quality. Studies in Higher Education, 42(8), 1455-1473.

Cai, H. M., \& Xu, X. D. (2014). Study on evaluation index system of undergraduate teaching in universities. Higher Engineering Education Research, (3), 177-180.

Cao, R. J. (2011). The Relationship between Teaching and Research of University Teachers: Problems and Solutions. Modern Education Management, (1), 52-55.

Charnes, A., Cooper, W. W., \& Rhodes, E. (1978). Measuring the efficiency of decision making units. European Journal of Operational Research, 2(6), 429-444.

Chen, J., \& Wu, W. (2014). An Exploration into the Influencing Factors of Teachers' Perception of TeachingResearch Relationship in Teaching Universities. Research in Higher Education of Engineering, (1), 97-102.

Clark, B. R. (1997). The modern integration of research activities with teaching and learning. Journal of Higher Education, 68(3), 241-255. https://dx.doi.org/10.1080/00221546.1997.11778982.

Fang, W. (2012). The development of transnational higher education in china: a comparative study of research universities and teaching universities. Journal of Studies in International Education, 16(1), 5-23. https://dx.doi.org/10.1177/1028315311410607.

Fulton, O., \& Trow, M. (1974). Research activity in American higher education. Sociology of Education, 47(1), 29-73. https://dx.doi.org/10.2307/2112166.

Li, B. B., \& Xu, X. D. (2011). Analysis and reflections on the imbalance between teachers' research and teaching abilities in university teachers' evaluation. Research in Higher Education of Engineering, (2), 76-81.

Li, Y. G. (2016). Intractable puzzle: New perspectives in the studies of relationship between university teacher's teaching and research. Journal of Education, 12(5), 60-67. https://dx.doi.org/10.14082/j.cnki.16731298.2016.05.008.

Li, Y. G. (2017). The Policy dilemma and reform of combining teaching and research: Based on the analysis of policy texts from 1987 to 2014. Journal of Southwest Agricultural University (Social Science Edition), 4(4), 84-92. https://dx.doi.org/10.13718/j.cnki.jsjy.2017.04.011.

Liu, X. J., \& Wu, H. F. (2010). The relation between teaching and research from the view of nonlinearity. Research in Higher Education of Engineering, (5), 77-87. 
Liu, X. Z. (2014). Building evaluation index system of teaching quality in colleges. China University Teaching, (7), 63-64.

Liu, X., Zhang, J., \& Wu, H. (2010). A survey on the teachers' understanding and management of the relationship between teaching and research. Research in Higher Education of Engineering, (2), 35-42.

Lu, G. S., \& Liu, L. (2006). Comparative study on scientific research efficiency of the universities affiliated with ministry of education in different regions. Fudan Education Forum, 4(2), 55-59.

Ramsden, P., \& Moses, I. (1992). Associations between research and teaching in Australian higher education. Higher Education, 23(3), 273-295.

Verburgh, A., Elen, J., \& Lindblom-Ylänne, S. (2007). Investigating the myth of the relationship between teaching and research in higher education: a review of empirical research. Studies in Philosophy \& Education, 26(5), 449-465. https://dx.doi.org/10.1007/s11217-007-9055-1.

Wang, X. (2017). The Theoretical Analysis of Scientific Research Outweighing Teaching in Universities A New Perspective. Journal of Dalian University of Technology (social sciences), 38(2), 128-132. https://dx.doi.org/10.19525/j.issn1008-407x.2017.02.020.

Wei Q. (2001). Data envelopment analysis. Chinese Science Bulletin, 46(16), 1321-1332.

Witte, K. D., \& Rogge, N. (2010). To publish or not to publish? on the aggregation and drivers of research performance. Scientometrics, 85(3), 657-680. https://dx.doi.org/10.1007/s11192-010-0286-5.

Witte, K. D., Rogge, N., Cherchye, L., \&Puyenbroeck, T. V. (2013). Economies of scope in research and teaching: a non-parametric investigation. Omega, 41(2), 305-314. https://dx.doi.org/10.1016/j.omega.2012.04.002.

Wu, H. F. (2011). Relationship between teaching and scientific research in the changing university field. Huazhong University of Science and Technology, 10, 88-88. https://dx.doi.org/10.7666/d.d186445.

Wu, H. F. (2012). Exploring paradigm of teaching and scientific research. Higher Education Exploration, (2), $19-24$.

Wu, H. F. (2012). Study on relationship between teaching and research from historical evolution perspective. Higher Education Exploration, (5), 98-103. https://dx.doi.org/10.3969/j.issn.1673-9760.2012.05.021.

Wu, L. B., \& Zhang, J. W. (2012). The relationship between research and teaching in universities: From the perspective of nonlinear thinking. Journal of Nanjing Normal University (Social Science Edition), (2), 8388. https://dx.doi.org/10.3969/j.issn.1001-4608-B.2012.02.013.

Xu, W. W., Wu, J. C., Jiang, B. B., \& Gong, F. H. (2011). Research on the evaluation system of teaching quality and its practice. Higher Education Research, (1), 100-103.

Yan, G. C. (2012). The unbalanced relationship between undergraduate teaching and research in research universities. Journal of Higher Education, (7), 38-45.

Yang, Y. Y., Liu, Y., \& Zhou, X. L. (2011). Integration of teaching and research in university: Problems, attributions and countermeasures. Education Research, (8), 55-58.

Zhang, G. P., Liao, J. Q., \& Liu, W. X. (2011). The influence of scientific research prospective earning on college teachers' unethical behavior. Higher Education Research, (5), 29-36.

Zhang, L. (2014). Study on Teaching Quality of College Teachers Based on Structural Equation Model. Statistics and Decision, (16), 61-63. 
Qin, Zhang, Zhu / Study on the Contribution Rate Variation of Teaching and Research of University Teachers Based on...

Zhao, J. (2014). Research on the teaching quality evaluation of college teachers based on DEA. China electronic education, (2).

Zhou, G.L., \& Ma, H. Q. (2013). Scholarship of teaching: A new framework of faculty development and evaluation. Education Research, (8), 37-47. 